\title{
Correction to: Applications of Carbon Nanotubes in Bio-Nanotechnology
}

T. Okpalugo, W. Ahmed and M. J. Jackson

\section{Correction to:}

Chapter 12 in: W. Ahmed and M.J. Jackson (eds.), Surgical Tools and Medical Devices, https://doi.org/10.1007/978-3-319-33489-9_12

The published version of the book contained an author in Chap. 12 (J. A. Byrne) who did not contribute to the chapter. We have removed him as a chapter author in the revised chapter. 